\title{
Curriculum Design in Professional Education: Theory and Practice
}

\author{
Maria Druzhinina*, Natalia Belkova, Elena Donchenko, Feng Liu, and Olga Morozova \\ ${ }^{1}$ Northern Arctic Federal University named after M.V. Lomonosov, Russia
}

\begin{abstract}
This article discusses the problem of ensuring the curricula quality. The aim of the theoretical research carried out by the authors is to clarify the perception of "curriculum design" with reference to international and domestic requirements for the curriculum development and quality assessment. During the research process, the "curriculum design" definition was given and curricula quality assessment criteria were selected. The authors conducted a comparative analysis of innovative, for different institutions, curricula which are implemented in the system of professional education: secondary, higher and vocational. In the article the authors focus on interactivity as the main criterion of the curriculum quality assessment. One of the results of implemented interactive working forms in education is to increase the level of students learning motivation. Involving not only teachers, but also students to the process of curriculum quality assessment promotes curriculum design development. This article covers the results of students' satisfaction level assessment with curriculum quality in the vocational education system. In conclusion, it is pointed out that curriculum design is a dynamic process which ensures the quality of specialists' training in the system of professional education
\end{abstract}

\section{Introduction}

The modern system of professional education is a multipurpose, multi-level, varied-profile scientific and educational complex, whose innovativeness lies in the realization of numerous functions: educational, scientific, social, cultural, communicational, international, economic, regulatory, leisureorganizational, and so on. The leading components of this system are secondary and higher education which solve tasks of secondary and higher professional qualification specialists training in colleges, institutes and universities. Another important component of professional education is vocational education. It can be represented within educational organizations in the form of commercially and non-commercially structural units and outside of them on the means of open education institutions, autonomous centers and socio-cultural institutions.

Undoubtedly, people are the primary value of the whole system of professional education, that is, all subjects of education, all representatives of university and non-university communities, who are interested in specialist training, acquiring, keeping and developing of demanded professional competencies and abilities in the whole life [1].

It is known that quality is a multidimensional concept. The quality of professional training is ensured if competence of specialists is formed in accordance with personal, public and state needs [2]. There is a question: how to provide the quality of professional education by meeting varied demanded? An effective instrument is required which should be regarded as a normative document and as a regulatory factor for the complicated teaching-methodological and scientific-educational process. Such an instrument, as authors assume, is a curriculum, on the design of which efficiency of the process of teaching future professionals depends. However, a problem is the lack of common views among scholars on curriculum design and on approaches to its quality assessment which leads to "failures" in understanding the concept of "curriculum design" and decreases quality assurance of the process of developing and implementing curricula.

The aim of the article is to analyze the concept of "curriculum design" and to apply its advancing ideas into the system of higher, secondary and vocational education. Tasks of the article include emphasizing of the compliance with international requirements for curriculum design, disclosing of its cross-cultural concept, choosing of criteria for quality assessment, comparing innovative curricula with selected criteria by authors, and presenting an evidence basis from practical point of view, which confirms the hypothesis of the need to ensure interactivity of curricula and constant enhancement to their design.

\section{Literature review}

* Corresponding author: m.druzhinina@ narfu.ru 
The issue of curriculum design is given quite a lot of attention [3-8]. The data, obtained by J.Y. Lee, S.H. Lee, J.H. Kim, reveal that teachers and scientists should pay more attention to the study of strategies for curriculum design [9].

The perception of "curriculum design" contains numerous essential characteristics. For many teachers and students, a curriculum and its design generally mean certain documented requirements for curricula, which are related to specific areas of knowledge. Some scientists are of the opinion that in this case the curriculum can be perceived as a response to administration requirements or quality assurances. A curriculum is often understood as a course, which is based on scientific interests, content and results, developed by the teaching staff and presented to students. According to R.W. Tyler, A.V. Kelly, this view reflects the conceptual basis of a training program based on products. J. Annala, M. Mäkinen note that some scientists suggest that scholars considering the curriculum of higher education perceive its design as a planned and dynamic process that reveals values and principles regarding learning, knowledge and disciplines, as well as the cultural and political goals of higher education [10]. Pinar provides an alternative strategy for understanding curriculum by studying interdisciplinary reconfiguration of knowledge about content of curriculum, and by using influence of academic knowledge on restructure learners' subjectivity [11].

Polar opposite scientist views reflect a relatively confined and reproductive approach to the interaction between research and teaching in curriculum development. As a result of the revision of the curriculum, it became possible to conceptualize core of disciplines, learning environment and changes in the world as an interactive process [10]. Their observations on the development process of the curriculum led to needs to introduce, study and comprehend phenomenon of the "curriculum design" perception.

Curriculum design is a "high level process", "curriculum development can be made more agile, flexible and responsive with the support of technology", "curriculum design entails two types of activity: educational design - the decisions taken by curriculum teams as they design the learning experience; and connected institutional processes - for example, information management, market research, marketing, quality enhancement, quality assurance and program and course approval" [12]. The design of a curriculum is treated as a technique. "Enhancements to design practices have included: a greater focus on the design process, allowing for light-touch approval events; richer ways of engaging stakeholders, including students, in the development of curricula; effective ways of representing and modelling curricula; reduction in the time spent on administrative tasks; improved understanding of educational principles as a benchmark for design quality" [12].

Karen Schweitzer assumes, "Curriculum design is a term used to describe the purposeful, deliberate and systematic organization of a curriculum (instructional blocks) within a class or course. In other words, it is a way for teachers to plan instruction. When teachers design curriculum, they identify what will be done, who will do it, and when". The same author defines three types of curriculum design and gives relevant advice [13].

John Biggs and his colleagues believe that "Curriculum design is a very important part of creating a contextually relevant and responsive teaching and learning environment for both lecturers and students. The curriculum contains the knowledge, skills and competencies that students need to master in order to move to the next level in their studies, and academic lecturers and tutors who are tasked with teaching this curriculum should, therefore, ensure that the curriculum is up to date, relevant, interesting and stimulating for students" [14].

A conceptual approach to the development of a curriculum is considered by varied scientists to be a strategy, a methodological basis, a guiding thread, a philosophy of collaboration of all stakeholders, a holistic position to stimulate the development of students' potential. Therefore, A. Klebansky, P.S. Fraser, after analyzing their curriculum and the approach to the design, believe that "As the University of Tasmania Teacher Education Information Literacy (UTAS TEIL) Conceptual Framework provides a strategic, holistic, equitable and sustainable model for collaborative curriculum design for information literacy (IL) and lifelong learning in teacher education, it has the potential to facilitate the development of teachers who are information literate individuals in their professional practice, able to be autonomous, self-directed lifelong learners, problem solvers, informed decision makers, creative and critical thinkers in the global teaching community". They also advocate that if to approach curriculum design systematically, then the concept of such a curriculum is portable to other learning conditions, hence the conclusion: "This would determine the transferability and adaptability of the UTAS TEIL Conceptual Framework into any context, and provide individuals within any discipline context with the capabilities that enable them to learn how to learn and gain subject content knowledge" [15]. Five curriculum design principles, proposed by Noel M. Meyers, Duncan D. Nulty, provide an approach to the development of intellectual abilities and lead to achievement of desired learning results: "To maximize the quality of student learning outcomes, we, as academics, need to develop courses in ways that provide students with teaching and learning materials, tasks and experiences which:

1. are authentic, real-world and relevant;

2. are constructive, sequential and inter-linked;

3. require students to use and engage with progressively higher-order cognitive processes;

4. are all aligned with each other and the desired learning outcomes;

5. provide challenge, interest and motivation to learn.

The effect of applying these principles is to manipulate the learning system in ways that require 
students to adopt a deep learning approach in order to meet the course's assessment requirements - which, in turn, meets the desired course learning outcomes [16]. Australian scientists A. Klebansky and P.S. Fraser assert that success is ensured by balancing efforts of students, the curriculum and teaching methods [15].

Nowadays, researchers agree that one of the key points of determining the quality of curriculum will be defining the correlation between learning outcomes and stated goals. Even R.W. Taylor pointed out basic requirements for formulating goals of curricula: taking into account the needs and interests of students and the requirements of modern life [17]. Scientists like KCB. Rao, D. Herlo confirm that professional educational programs must meet conditions of the labor market [18], be competitive [19]. That is, goals and results of the programs should be adapted to the modern requirements, which are imposed on a specialist like a professional.

The solution to this problem is facilitated by implementing competency-based approach to professional education, in which competence is seen as the result of teaching. According to D. Herlo, competence is firstly formed as curriculum objectives, then transferred to the status of teaching principles, and ultimately considered results of mastery. The use of the competence-based approach to curriculum design also appeared in works of J. Villalobos, O. González [20].

When selecting criteria for quality of curricula, content is highlighted, which is of great importance both for learners and, definitely, for the society [19]. Each curriculum contains a clear description of the level of education (secondary, higher, vocational), teaching subjects, its duration, quantity of study hours, that is, the parameters of the curriculum [17]. Complexity of content of the curriculum relies on them. Moreover, these requirements must also be met by curricula.

In Curriculum Design Project 2061 by American Association for the Advancement of Science, it is stated that "block planning" is more often applied in modern curriculum design, so it is called modularity by D. Herlo. A unit of curriculum, built by a block-modular type, becomes a module with aims at educational goals. Within each module, competence which demonstrates a function of profession is formed. In a curriculum consisting of modules, its content is structured and has a clear sequence. Moreover, it is flexible and able to take individual educational trajectories of learners into account [17, 21, 22].

As the analysis of literature shows, one of criteria for concerning curricula is the degree of implementing educational technology. Key factors in choosing suitable technologies are the qualification of faculty, their pedagogical experience and the level of students' readiness for different types of teaching.

In recent years, foci of researchers have been on the relationship between traditional and innovative educational technology. According to Corbett, Tims, Turner and Nelson, one of the tasks of educators is to create an environment that is attracting for students [23]. It is noteworthy that there is attention to the results of the Curriculum Design Project 2061, in which innovative technologies are regarded as additional opportunities for improving effectiveness of teaching: group work, seminars, independent research, projects, etc. [17]. Y. Vovides, S. Inman [24] in their research also emphasize the feasibility and advisability of using an open online space to expand educational opportunities of all groups of students. Curricula imply the description and usage of optimal educational technology.

With all certainty, it can be asserted that assessment in pedagogy is viewed as a criterion for effectiveness of curricula. According to KCB. Rao, assessment is feedback, in which students and teachers take part. The author distinguishes three types of assessment: selfassessment, peer review (assessment by students of each other), teacher assessment [19]. Assessment is very important for identifying drawbacks in the implementation of curricula, and is the basis for their adjustments.

We generalize points of view on curriculum design of different scholars and come up with our opinion. Therefore, curriculum design is: a complex process, presupposing a vision of an educational strategy and prospects of the curriculum; discussion and development of its concept; designing and modeling of content; search for optimal ways and technologies for realization. The ideal way to create an innovative curriculum is carried out through network interaction with employers and partners of other institution. Quality of the design is ensured by constant elaboration of the concept and content, satisfaction of students' needs, and assessment of results and their development dynamics. It is important to note that curriculum design is necessary not only for teachers, but also for students, because a conceptually constructed curriculum along with a clear teaching organization, and an assessment system motivates them to achieve their set results.

Concerning defining criteria for quality of curriculum, there are several points of view, the analysis of which allowed us to identify the primary ones: correlation of learning outcomes and set goals, choices of curriculum content, usage of educational technology and assessment.

\section{Research methodology}

The methodology of our research was a trajectory of a collective work (seven researchers) from analysis of curriculum through studying theories of curriculum design for empirical research.

At the first stage during methodological seminars, various levels and forms of a curriculum were collectively analyzed by authors, including secondary, higher and vocational education. From all our curricula, developed by us, the most innovative ones were selected for institutions of different types: Northern Arctic Federal University, Arkhangelsk pedagogical college, Arkhangelsk region institute of open education, Educational and methodical center for civil defense, emergency situations and fire safety. All these organizations are located in Arkhangelsk in the North of Russian Federation. Below there are core curricula analyzed by us: "Foreign language for scientific 
purposes"; "Organization of children's various activities and communication"; "Organization of classes on basic general educational programs for preschool education"; "Modern approaches to teaching in preschool education"; "Development of coherent speech of children of preschool age: methods, technologies and techniques"; "Professional standard "Teacher" as the basis for professional development of an educator"; "A vocational educational program for improving the qualifications of managers and regular employees (specialists) in the Organization of civil defense and territorial subsystem for preventing and eliminating emergency situations in the Arkhangelsk region". In the last curriculum peer review was documented and carried out with reference to requirements for expertise of curriculum in Russia. While analyzing, an idea about a comparative analysis (at first sight incomparable!) of curricula for a purpose of sharing best practices between different types of educational organizations occurred. Besides, by conversation and discussions, it became necessary to turn to the notion of "Curriculum Design", which required special study.

At the second stage of the study, Russian and foreign literature resources about curriculum design were studied. More than 50 works were studied, from which the fundamental ones are presented in the literature review and included in the reference. Particular attention was paid to the selection of criteria for quality of curricula. As a result, from a large set of scientist's opinions, such criteria as conceptual ideas, content, modularity, technology, and assessment of curriculum implementation were chosen.

At the third stage of the study, in the process of comparing the author's curricula, recommendations were given for their improvement.

In the Arkhangelsk pedagogical college, an experiment was conducted by distance learning, providing an interactive (new for this institution) nature of a curriculum. In the opinion of authors, the curriculum implementation in a distance form, on the one hand, implies a measurement of the level of students' motivation development, on the other hand, it can stimulate motivation of students for learning activities. Accordingly, the experimental work in the college indicates a comparative analysis of the degree of motivation formation of students before and after the implementation of the curriculum using distance technology. In the experiment 64 first-year students of the college, studying pedagogy, participated.

Another direction of experimental work was to identify levels of satisfaction with the quality of curricula (vocational educational) in the Arkhangelsk region institute of open education. Assessment of the "Modern approaches to teaching in preschool education" were carried out by students through a questionnaire. 61 people took part in the experiment.

Both qualitative and quantitative approaches were applied in research in the article. Qualitative methods were used to collect deep and comprehensive data about curricula, like interviews with students. To collect data from students, the quantitative method was applied. In total, this study was designed and implemented as a mixed study.

\section{Description of research results}

As a result of the analytical work at the first stage of the study, it can be concluded that curriculum design is defined by the pedagogical process structure and includes the following components:

- target: goals and tasks implemented in specific educational conditions;

- content: defining the entity of knowledge formed by value orientations, experience and communication;

- activity: featured forms, ways, means of organization and implementation of pedagogical interaction, aimed at realizing goals and tasks, mastery of the curriculum content;

- productiveness: achieved results and the degree of pedagogical process effectiveness, which ensure the quality management of educational activities;

- resource: image of pedagogical process realization and maintenance conditions.

Table 1 shows that invariants of the curricula, analyzed by us, created in accordance with ideas of competence-based approach, are precisely these components.

Table 1. Fundamental structural components of curricula.

\begin{tabular}{|c|c|c|c|}
\hline $\begin{array}{c}\text { Structural } \\
\text { components } \\
\text { of a } \\
\text { curriculum }\end{array}$ & $\begin{array}{c}\text { Secondary } \\
\text { Professional } \\
\text { Education }\end{array}$ & $\begin{array}{c}\text { Higher } \\
\text { Education }\end{array}$ & $\begin{array}{c}\text { Vocational } \\
\text { Education }\end{array}$ \\
\hline Title page & + & + & + \\
\hline $\begin{array}{c}\text { Objectives, } \\
\text { Tasks, } \\
\text { Results }\end{array}$ & + & + & + \\
\hline $\begin{array}{c}\text { Educational } \\
\text { plan and } \\
\text { thematic } \\
\text { plan }\end{array}$ & + & + & + \\
\hline $\begin{array}{c}\text { Content of } \\
\text { the } \\
\text { curriculum } \\
\text { themes }\end{array}$ & + & + & + \\
\hline $\begin{array}{c}\text { Organization } \\
\text { al and } \\
\text { pedagogical } \\
\text { conditions }\end{array}$ & + & + & + \\
\hline $\begin{array}{c}\text { Results } \\
\text { control and } \\
\text { assessment }\end{array}$ & + & + & + \\
\hline Bibliography & + & + & + \\
\hline
\end{tabular}

A variable component of curricula is provided by modularity, employed technologies, differential nature of content and design as a process of curricula development.

The basis of curriculum design is the understanding that it is as a set of organizational and pedagogical conditions for implementing educational system requirements and features of professional training. It is 
formed independently by an institution taking into account students' educational needs and regional demands for personnel.

At the stage of the experimental part of the research at the Arkhangelsk pedagogical college, the following results were obtained. In order to determine understanding of college students' motivational environment, there was used a method of students' learning motivation diagnostics, whose aim was to study their motivations for learning activities [25].

We studied motivations for students' learning at Arkhangelsk pedagogical college. According to the results of the first stage analysis, among the students' motivations there are dominating professional and communicative ones which are related with a desire to communicate, to receive as much information as possible, and to make progress in professions.

During the academic year with the help of these college students there were implemented educational curricula, which included distance technology. The experiment results showed positive dynamics. It can be seen on the "Professional motivations" scale where the dynamics is related to professional activity effectiveness; on the "Motivations for creative self-realization" scale where the dynamics is related to identification and development of their own creative abilities; on the "Learning and cognitive motivation" scale where the dynamics is related to students learning activities and shows their desire to gain new knowledge and skills, and readiness to find new information by themselves.

Obtained data are illustrated on scales in the diagram (Figure 1):

- scale 1. Professional motivations;

- scale 2. Motivations for creative self-realization;

- scale 3. Learning and cognitive motivations
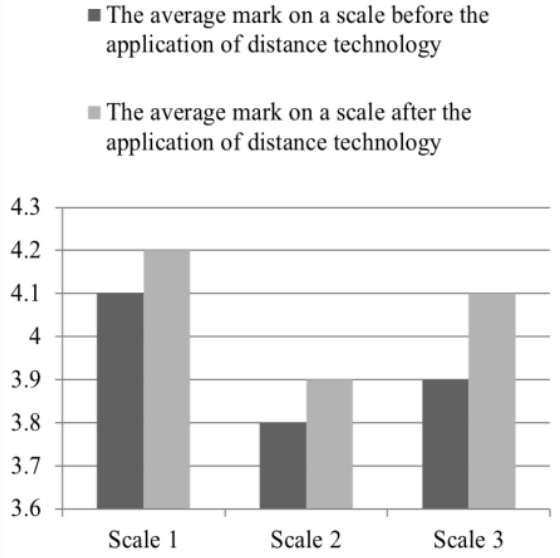

Fig. 1. Changes in motivations for learning activities in a student group.

In this way, the comparison of levels of professional motivations, learning and cognitive motivation, motivations for creative self-realization of college students before and after the implementation of curricula with distance technology demonstrates a positive dynamics.
The study results of the curricula quality satisfaction level in Arkhangelsk region institute of open education were very demonstrative for us. Satisfaction was assessed by the seven indicators, and the obtained data are presented in Table 2 .

Table 2. Levels of curricula quality satisfaction (by the example of Arkhangelsk region institute of open education).

\begin{tabular}{|c|c|c|}
\hline № & Indexes of satisfaction & $\begin{array}{c}\text { Obtained } \\
\text { results }\end{array}$ \\
\hline 1 & $\begin{array}{c}\text { Training course content for } \\
\text { advancing qualification is practically } \\
\text { oriented }\end{array}$ & $93.7 \%$ \\
\hline 2 & $\begin{array}{l}\text { Teaching material is structural, } \\
\text { logically constructional, and is } \\
\text { presented consistently, } \\
\text { understandably }\end{array}$ & $96.7 \%$ \\
\hline 3 & $\begin{array}{l}\text { Varied ways of solving professional } \\
\text { problems are provided }\end{array}$ & $94.6 \%$ \\
\hline 4 & $\begin{array}{l}\text { Claimed results of professional } \\
\text { development in a curriculum have } \\
\text { been achieved in full scale }\end{array}$ & $92.9 \%$; \\
\hline 5 & $\begin{array}{l}\text { Enough information about teaching } \\
\text { organization is provided }\end{array}$ & $96.9 \%$ \\
\hline 6 & $\begin{array}{l}\text { A friendly working atmosphere for } \\
\text { professional communication is } \\
\text { created }\end{array}$ & $99.6 \%$ \\
\hline 7 & $\begin{array}{l}\text { Working materials are convenient } \\
\text { for using in classes and useful for } \\
\text { professional activities }\end{array}$ & $96.5 \%$ \\
\hline
\end{tabular}

The total satisfaction rate was $95.8 \%$, which may indicate the quality of the curriculum implementation. The obtained data was confirmed in the process of analyzing the curricula, implemented in Arkhangelsk region institute of open education. It is noted that the curricula contain latest topics, use modern technologies, have differential nature of content and depend on categories of students who also have the opportunity to choose forms of teaching and content.

\section{Conclusions}

In this way, the methodological basis of curriculum design is the module-competence based approach, which is a unified system for defining objectives, selection and construction of a teaching process content, organizational and technological support of students preparing on the basis of the competencies identification that ensure productiveness and effectiveness of professional activities. The means of achieving the result 
is a modular construction of the professional education structure and content.

The results of the conducted empirical research have also made it possible to conclude that the introduction of a distance learning system, and, sequentially, the realization of the principle of interaction allowed to improve the quality of the curriculum because this process has contributed to dynamics of the shaping students' motivations for learning activities at Arkhangelsk pedagogical college.

In the process of experimental work at the pedagogical college, we identified pedagogical conditions that ensure interactivity of curricula implementation:

- the development of a comfortable educational environment at college that fosters students' personal development;

- the formation of methodological conditions that allow a student to navigate the site and study successfully;

- the creation of organizational and managerial conditions namely, ways to motivate students, support students' autonomy, assist teachers, assessment system within a discipline.

Implementation of these conditions allows a distance learning system designed for a specific group of students.

Including students in the process of assessment of the curricula quality makes it possible to work on their design, and thus to improve the quality of the teaching process in the system of professional education.

\section{Acknowledgment}

The authors of the article express special gratitude to Olga Istomina, a teacher in Arkhangelsk region institute of open education, and Elena Solovyova, a teacher in the Educational and methodical center for civil defense, emergency situations and fire safety, for their active participation in the implementation of the research project "Curriculum design in the system of professional education" and the collaborative analysis of the results of the research.

\section{References}

1. M. Druzhinina, Foreign experience in language education, Modern language education in the system "bachelor - master - graduate school", (Pomor University, Arkhangelsk, 2009)

2. M. Druzhinina, The development of the linguistic education policy of the University as a factor of ensuring specialists training quality, (Pomor University, Arkhangelsk, 2007)

3. N. Mirriahi, D. Alonzo, B. Fox, RLT 23, 1-14 (2015)

4. K. Elissa, "Title of paper if known," unpublished.

5. C. Shangzhi, CE 1(3), 184-195 (2010)

6. S. Karimi, A.R. Nasr, M. Sharif, JEL 1(2), 143-152 (2012)

7. K.A. Livingstone, JBM\&SSR 3(5), 1-17 (2014)

8. D. Drits-Esser, L.A. Stark, EJSE 19(8), 1-27 (2015)
A. Vuong, T. Nixon, B. Towle, Proceedings of the 4th International Conference on Educational Data Mining, 211 (2011)

9. J. Lee, S.H. Lee, J. Kim, Nurse Educ. Today 64, 4248 (2018)

10. J. Annala, M. Mäkinen, TCI 8(1) (2011)

11. W.F. Pinar, The synoptic text today and other essays. Curriculum development after the reconceptualization (Peter Lang, New York, 2006)

12. Enhancing Curriculum Design with Technology. Outcomes the Jisc Institutional Approaches to Curriculum Design Programme, from https://www.jisc.ac.uk/sites/default/files/enhancingcurriculum-design.pdf

13. K. Schweitzer Curriculum Design: Definition, Purpose and Types, from https://www.thoughtco.com/curriculum-designdefinition-4154176

14. J. Biggs, C. Tang, Teaching for Quality Learning at University (McGraw Hill Education \& Open University Press., Maidenhead, 2007)

A. Klebansky, P.S. Fraser, AJTE 38(11), 102-125 (2013)

15. N.M. Meyers, D.D. Nulty, Eval. High. Educ. 34(5), 565-577 (2009)

16. Resources for science literacy : professional development. by Project 2061 (American Association for the Advancement of Science), (Oxford University Press, New York, 1997)

17. D. Herlo, JPE, 7(2), 36-41 (2015)

18. KCB. Rao, JEE Special Issue, 138-140 (2015)

19. J. Villalobos, O. González, IJEE, 28(4), 880-891 (2012)

20. J.M. Lightfoot, CIIMA 6, 6 (2006)

21. M. Tucker, 9 Building Blocks for a World-Class Education System, (DC: National Center on Education and the Economy, Washington, 2016)

22. K.S. Corbett, H. Tims, G.E. Turner III, J.D. Nelson, ASEE Annual Conference \& Exposition, 7, 57745791 (2012)

23. Y. Vovides, S. Inman, Open Learning and Formal Credentialing in Higher Education: Curriculum Models and Institutional Policies (IGI Global, Queensland, 2016)

24. N.Ts. Badmaeva, The influence of the motivational factor on the development of mental capacity (VSGTU, Ulan-Ude, 2004) 